\title{
Ventilatory function changes over a workshift
}

\author{
H D DIMICH ${ }^{1}$ AND T D STERLING ${ }^{2}$ \\ From the Department of Kinesiology ${ }^{1}$ and the Faculty of Interdisciplinary Studies, ${ }^{2}$ Simon Fraser \\ University, Burnaby, British Columbia, Canada
}

\begin{abstract}
Thirty-four production workers at three chemical plants were tested for acute changes in lung function over the course of their three-day, twelve-hour workshift. Mean percentages of the predicted lung function indices (FVC, FEV, and $\mathrm{FEF}_{25-75}$ ) showed a workshift decrement, particularly evident in the evening shift. A workweek effect was shown in that no recovery in mean $\% \mathrm{FEV}_{1}$ and $\% \mathrm{FEF}_{25-75}$ was shown by the last working day. Diurnal variation in respiratory function was regarded as being only partly responsible for the observed workshift effect.
\end{abstract}

The major objective of this study was to determine if an acute change in lung function was apparent in chemical workers over the course of their threeday, 12-hour workshift.

A workshift decrement in respiratory function attributable to the working environment was first shown by McKerrow et al ${ }^{1}$ in their study of cotton workers. Subsequent studies on hemp and textile workers, ${ }^{2} 3$ coal miners, ${ }^{4}$ and toluene-diisocyanate workers ${ }^{5}$ have found similar work-related changes in lung function. The rationale for measuring an acute decline in ventilatory capacity over a workshift is that it may "serve as a biological monitor of the working environment," and "might indicate liability to later permanent respiratory disability." 6

Production workers employed at three chemical firms were the subjects of the investigation. Local 5 of the Pulp, Paper, and Woodworkers Union of Canada sponsored the study, which was undertaken with management co-operation in September and October 1979.

\section{Methods}

The production workers at all three chemical plants worked on a rotating three-day 12-hour workshift schedule. The day shift was scheduled from $6 \mathrm{am}$ to $6 \mathrm{pm}$; the evening workers relieved them for the subsequent $6 \mathrm{pm}$ to 6 am shift. A three-day break followed the completion of the three-day 12-hour working week.

While 58 production workers were tested altogether, only 34 Caucasian production workers were analysed as they fulfilled the requirement of com-

Received 20 May 1980

Accepted 31 July 1980 pleting all six tests. Their age ranged from 22 to 57 $($ mean $=32.4)$, and they had been employed as production workers an average of $4 \cdot 2$ years with a range of less than one to 18 years.

Smoking habits were fairly evenly divided. Of the 21 day-shift workers and 13 evening workers, 11 were non-smokers, 13 current smokers, and 10 past smokers. Analysis of variance showed no significant differences $(p>0.05)$ between the day and evening workers with respect to their age, height, duration of employment, and days off before the start of the workweek.

Pulmonary function testing was conducted on site for a one-week period at each chemical plant to accommodate four complete three-day shifts. The testing was done before and after the completion of the shift on each consecutive day of the three-day working week. Altogether, six test were obtained on each subject. The lung function measurements were recorded using the Hewlett Packard model 47804A pulmonary calculator system. Machine-calibration was carried out regularly before each morning and evening session and was externally adjusted by syringe calibration at least weekly.

The pulmonary test used was the standard forced vital capacity (FVC) manoeuvre. While seated and with noseclips on, the subject inspired to full lung inflation and then exhaled into the heated pneumotach as rapidly, completely, and forcibly as possible. At the first session a minimum of five FVC manoeuvres were performed, while later sessions entailed a minimum of three tests to obtain the best possible effort for analysis. The criterion for the best test was the highest sum of the indices of FVC and forced expiratory volume in one second $\left(\mathrm{FEV}_{1}\right)$.

Each measured lung function parameter was 
automatically adjusted as a percentage of the predicted value based on standardised norms that are dependent on the sex, age, and height of the individual. The standard equations used to predict expected lung function values for Caucasian men aged over 20 were those derived by Morris et al. ${ }^{\text {? }}$

$\mathbf{H}=$ height in inches. $\mathbf{A}=$ age in years.

$\mathrm{FVC}=0.148 \times \mathrm{H}-0.025 \times \mathrm{A}-4.241$

$\mathrm{FEV}_{1}=0.092 \times \mathrm{H}-0.032 \times \mathrm{A}-1.26$

$\mathrm{FEF}_{25-75}=0.047 \times \mathrm{H}-0.045 \times \mathrm{A}+2.513$

\section{Results}

For the day and evening workers the percentage of the predicted lung function values, \%FVC, $\% \mathrm{FEV}_{1}$, and percentage of maximal mid-expiratory flow $\left(\% \mathrm{FEF}_{25-75}\right)$ were analysed for changes over a shift, between each workday, and over the three-day working week. Changes in the percentages of the predicted lung function indices were evaluated, rather than absolute measures of volume and flow, to account for differences in lung capacity due to ageing and size.

An analysis of variance with repeated measurements was applied to determine the significance of the time of the shift (start or end), the day of the working week (first, second, or third), and the type of shift (day or evening) on the values of $\% \mathrm{FVC}$, $\% \mathrm{FEV}_{1}$, and $\% \mathrm{FEF}_{25-75}$. A significant main effect of time of shift as well as a significant interaction of time with type of shift was shown for all the indices $(p<0.05)$. While the overall means for the end of the shift were lower than at the start, it was for the evening shift workers that a major workshift decrement was apparent (see figs 1, 2, 3). Over the working week the evening workers showed average shift reductions of $3.8 \%, 5 \cdot 1 \%$, and $9.1 \%$

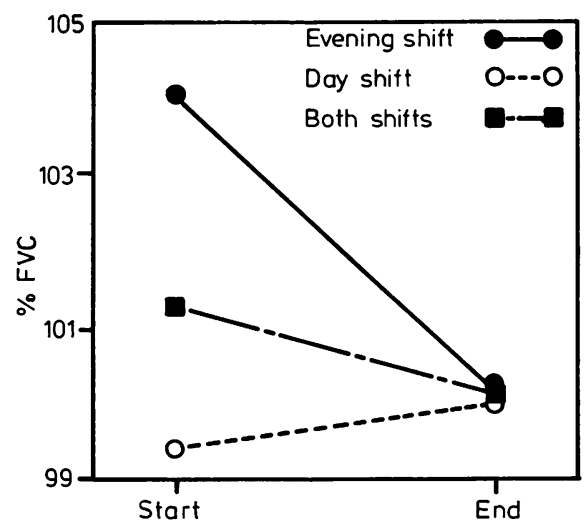

Fig 1 Average workshift changes in $\% F V C$.

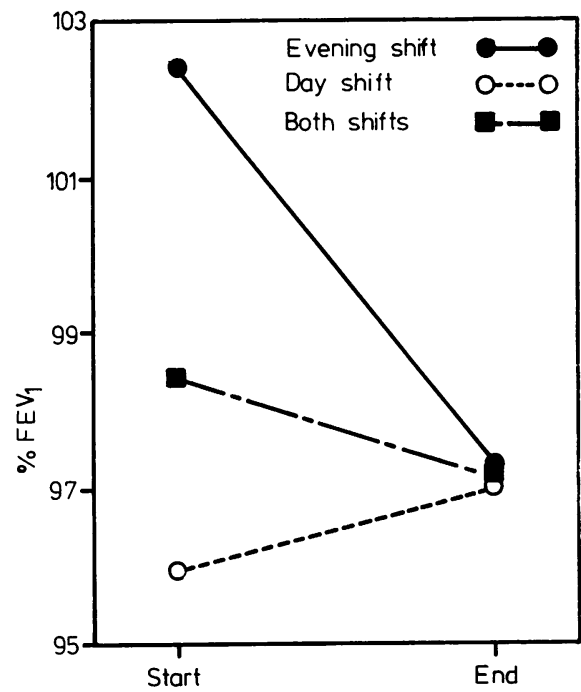

Fig 2 Average workshift changes in $\% F E V_{1}$.

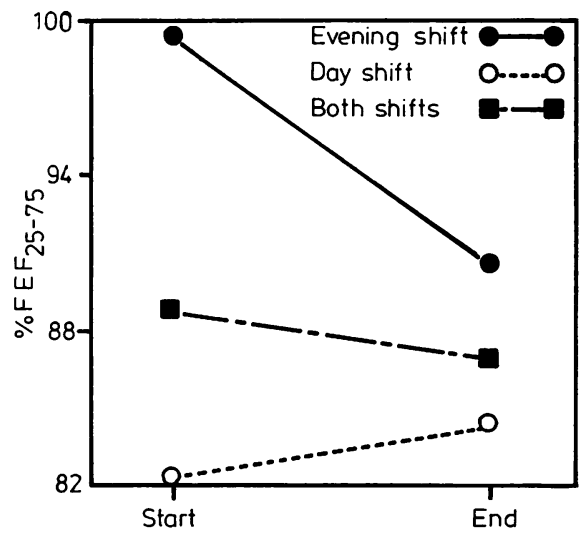

Fig 3 Average workshift changes in $\% F E F_{25-75}$.

for the respective indices of $\% \mathrm{FVC}, \% \mathrm{FEV}_{1}$, and $\% \mathrm{FEF}_{25-75}$. Figure 4 depicts a differential workshift response of percent maximal mid-expiratory flow that is dependent on the type of shift.

For the lung function indices of $\% \mathrm{FEV}_{1}$ and $\% \mathrm{FEF}_{25-75}$ an effect of day of the working week was also evident. Post-hoc analyses using Tukey's test of honesty significant differences showed that the average day $3 \% \mathrm{FEV}_{1}$ value of $96.7 \%$ was significantly less than the value of $99.2 \%$ found for day 1 . With regard to the $\% \mathrm{FEF}_{25-75}$ parameter both the day 2 mean of $86.6 \%$ and the day 3 mean of $84.5 \%$ were significantly different from the average of $92.3 \%$ found for day 1 ( $p<0.05)$.

The "working-week effect" for each subject was 


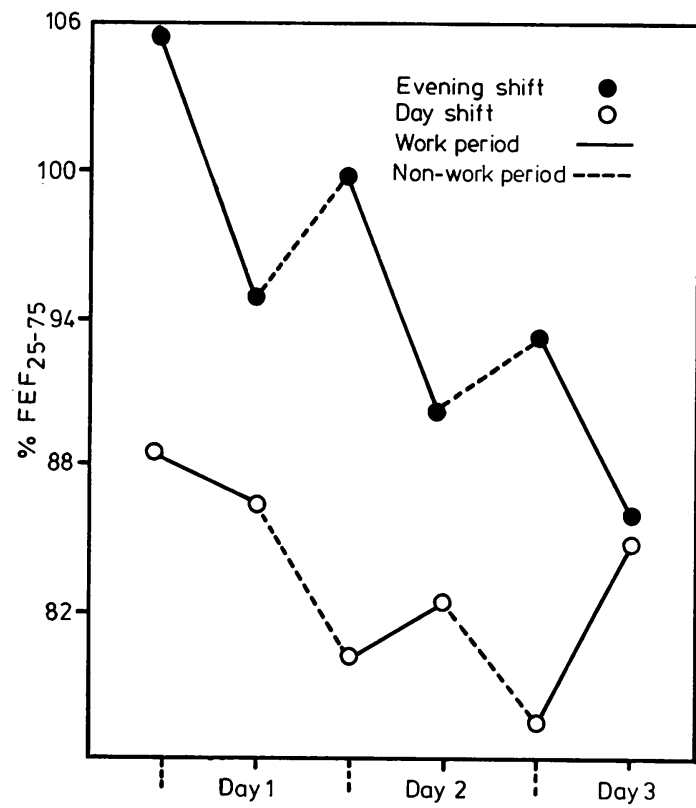

Fig 4 Daily workshift changes in mean $\% F E F_{25-75}$.

determined by subtracting the mean value of the start and end of the last day of work from that of the first workday. For the lung function parameters of $\% \mathrm{FEV}_{1}$ and $\% \mathrm{FEF}_{25-75}$ the working-week effect was found to result in significant mean decrements of $2.5 \%$ and $7.8 \%$ respectively.

\section{Discussion}

This study replicated the findings of previous studies on other industrial workers, in that an acute decrement in respiratory function was observed at the end of a workshift. ${ }^{4}$ Over the three-day working week the production workers showed an average workshift decrease of $1.1 \%$ in their $\% \mathrm{FVC}$ and $\% \mathrm{FEV}_{1}$ values, and for $\% \mathrm{FEF}_{25-75}$ a $2 \cdot 1 \%$ decrement was shown. Similarly, Valic and Zuskin ${ }^{3}$ in their 1977 study of textile workers found $2.1 \%$ and $3.8 \%$ reductions in the initial $\mathrm{FVC}$ and $\mathrm{FEV}_{1}$ values respectively over an eight-hour work period.

The evening production workers in particular showed a large decrease in lung function over the course of the 12-hour shift. Conversely, for the dayshift workers, slight increases in the average lung function values were shown. Walford $e t a l^{8}$ and Guberan et $a l^{9}$ also found differential lung function responses according to the period covered in the working shift. Day workers showed a slight increment in their FEV measurements by the end of their shift. Afternoon and evening shift workers conversely showed a general pattern of lung function decrement. They concluded that a diurnal effect was in operation that negated efforts at showing any effect due to exposure to respiratory irritants at work.

The phenomena of a circadian rhythm in pulmonary function has been shown both in normal and diseased individuals.10-13 In all studies for FVC, $\mathrm{FEV}_{1}$, and peak expiratory flow rates an increase is shown throughout the morning until a peak is reached at midday; over the late afternoon and evening these values decrease, reaching a low point about 6 am.

While Walford et $a l^{8}$ found that their control group of day workers showed increases in respiratory function over the course of the working day, normal day-shift cotton workers showed less of an increase, while their byssinotic co-workers even showed a decrease in FEV by the end of the shift. McKerrow et al ${ }^{1}$ found that when cotton workers were measured while working away from their usual dusty working environment, their workshift fall in lung function, as determined by indirect maximal breathing capacity, was reversed or reduced. Thus a less than expected increase or a decrease in daytime respiratory function may be indicative of acute dysfunction.

Figure 4 illustrates the pattern of changes in $\% \mathrm{FEF}_{25-75}$ for the day workers. For the first day back at work, rather than the expected increase a decrease in respiratory function is shown. In addition the second workday shows a smaller increase in $\% \mathrm{FEF}_{25-75}$ than is found in the last working day. This start-to-end of the workshift pattern of decrement or less than expected increment may be indicative of acute respiratory dysfunction.

In our study full recovery of any shift decrement in lung function during the workweek was generally not apparent. Over the three-day workweek a progressive impairment of respiratory capacity was evidenced by the "working-week effect" of an average decrement in the mean $\% F^{2} V_{1}$ and $\% \mathrm{FEF}_{25-75}$ values on the last workday as compared to the first. Peters et al ${ }^{5}$ chose to examine the effect of one week's exposure by comparing the last day end-of-shift pulmonary function values with those of the start of the first day. They also found that while FVC tended to recover during the week, FEV did not. According to McKerrow et al ${ }^{1}$ in their 1958 study on cotton workers, "The incomplete recovery of ventilatory capacity over a single night is to be expected because elimination of dust from the bronchial tree takes more than 12 hours" (p 82).

Lapp et al ${ }^{14}$ conclude that, "The normal diurnal variation in ventilatory capacity cannot account for our findings." This conclusion also seems appropriate for our study. A complicating factor is that 
the workers are on a rotating shift system with a three-day rest interval. Entrainment may not be complete, as a change of shift will take a few days to adjust to a new physiological rhythm. ${ }^{8}$

As to which factors of the working environment may have affected an acute decrement in lung function, the production workers are often exposed to several chemical hazards. These include chlorine and hydrochloric acid at two of the chemical plants and benzene and benzaldehyde at the other. Unfortunately, the management at all three chemical plants refused to allow on-site atmospheric monitoring, a not uncommon occurrence in occupational health. The workers are typically exposed to levels that hover about the permissible threshold limit values. Chlorine in particular has been shown to evoke respiratory irritation at concentrations much below the current threshold limit value of $1 \mathrm{ppm} . .^{15}$ Conclusive evidence as to workplaceinduced acute decrements in lung function would require further experiments using accurate measures of exposure levels and a control group of nonexposed workers.

\section{References}

${ }^{1}$ McKerrow CB, McDermott M, Gilson JC, Schilling RSF. Respiratory function during the day in cotton workers: a study in byssinosis. $\mathrm{Br} J$ Ind Med 1958;15:75-83.

${ }^{2}$ Bouhuys A, Barbero A, Lindell SE, Roach SA, Schilling RSF. Byssinosis in hemp workers. Arch Environ Health 1967;14:533-44.

${ }^{3}$ Valic F, Zuskin E. Respiratory-function changes in textile workers exposed to synthetic fibers. Arch Environ Health 1977;32:283-7.

4 Reger R. Ventilatory function changes over a work shift for coal miners exposed to diesel emissions. In: Bridbord
K, French J, eds. Toxicological and carcinogenic health hazards in the workplace. Proceedings of the first annual National Institute for Occupational Safety and Health scientific symposium. Washington: Department of Health, Education, and Welfare, Pathotox Publ Inc, 1978:346-7.

${ }^{5}$ Peters JM, Murphy RLH, Pagnotto LD, Van Ganse WF. Acute respiratory effects in workers exposed to low levels of toluene diisocyanate (TDI). Arch Environ Health $1968 ; 16: 642-7$.

${ }^{6}$ Berry G, McKerrow CB, Molyneux MKB, Rossiter CE, Tombleson JBL. A study of the acute and chronic changes in ventilatory capacity of workers in Lancashire cotton mills. Br J Ind Med 1973;30:25-36.

${ }^{7}$ Morris JF, Koski A, Johnson LC. Spirometric standards for healthy non-smoking adults. Am Rev Resp Dis $1971 ; 103: 57-67$.

${ }^{8}$ Walford J, Lammers B, Schilling RSF, Van der Hoven van Genderen D, Van der Veen YG. Diurnal variation in ventilatory capacity. An epidemiological study of cotton and other factory workers employed on shift work. Br J Ind Med 1966;23:142-8.

${ }^{9}$ Guberan E, Williams MK, Walford J, Smith MM. Circadian variation of FEV in shift workers. Br $J$ Ind Med 1969;26:121-5.

${ }^{10}$ Lewinsohn H, Capel L, Smart J. Changes in forced expiratory volumes throughout the day. $\mathrm{Br} \mathrm{Med} J 1960$; : 462-4.

${ }^{11}$ Reinberg A, Gervais P. Circadian rhythms in respiratory functions, with special reference to human chronophysiology and chronopharmacology. Bulletin de Physiopathologie Respiratoire 1972;8:663-75.

12 Hruby J, Butler J. Variability of routine pulmonary function tests. Thorax 1975;30:548-53.

${ }^{13}$ Hetzel MR, Clark TJH, Brown D. Normal circadian rhythms in peak expiratory flow rate. Thorax 1978;33: 668.

${ }^{14}$ Lapp NL, Hankinson JL, Burgess DB, O'Brien R. Changes in ventilatory function in coal miners after a work shift. Arch Environ Health 1972;24:204-8.

${ }^{15}$ Committee on Medical and Biological Effects of Environmental Pollutants. Chlorine and hydrogen chloride. Washington: Division of Medical Sciences, National Research Council, National Academy of Sciences, 1976. 